
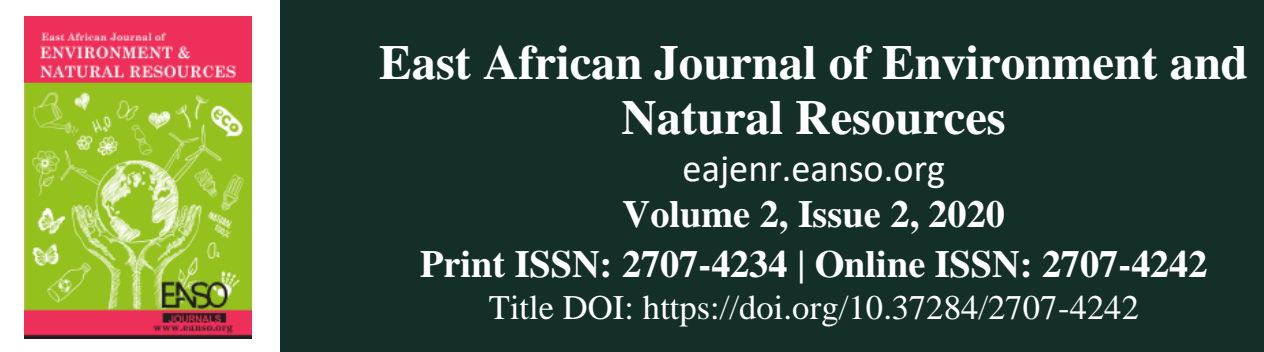

Original Article

\title{
Climate Change Adaptation Strategies among Tobacco Small Scale Growers at Kiloleli Village in Sikonge District, Tanzania
}

\author{
Canisius John Kayombo ${ }^{1,2, *}$, Lambert Komba ${ }^{2}$ \& Almas Kashindye ${ }^{2}$ \\ ${ }^{1}$ Department of Botany, College of Natural and Applied Sciences, University of Dar es Salaam, Tanzania \\ ${ }^{3}$ Forestry Training Institute, Olmotonyi. P. O. Box 35091, Dar es Salaam, Tanzania. \\ *Author for Correspondence email: kayombo33@yahoo.co.uk or kayombocanisius@ gmail.com \\ ORCID: https://orcid.org/0000-0002-8149-895X
}

Article DOI: https://doi.org/10.37284/eajenr.2.2.149

Date Published: ABSTRACT

05 June 2020 Climate change is being discussed regularly at the global level. The study was Keywords: among tobacco small scale growers at Kiloleni Village in Tabora region, Tanzania. Yamane formula was used to calculate the sample size. Questionnaires Climate Change Indicators,

Small Scale Growers, Adaptation Strategies, Kiloleli Village, Sikonge District. and checklists were used as tools for data collection in the field. Secondary data were obtained by reviewing various published and unpublished documents. Data were analysed using the statistical package of social sciences (SPSS) software. The indicators of climate change on small scale tobacco growers based on the respondents were an increase in temperature, crop wilting, increase in insects, decrease in river water, soil dryness, strong wind, infertility of soil, crop dwindled growth, low rainfall, an increase of diseases, dryness of wells and poor air quality. The identified effects of climate change were drought, floods, hunger, soil erosion, a decrease of area for pasture, death of crops, dryness of river and production is still decreasing and increase of diseases to tobacco. Climate change effects were revealed to be such a burning issue to the small-scale growers that needed strategies to minimize the effects of climate change. Among strategies for reducing the effects of climate change were tree planting as the most useful way of adapting to climate change of all other strategies. The other adaptation strategies to the effects of climate change were drought-resistant crop cultivation, education, agroforestry practices, formulation of bylaws, use of alternative sources of energy and crop rotation. Climate change has shown severe damage to small scale tobacco growers and thus reducing crop yields. This study sets the following recommendations; tree planting, application of agroforestry, education 
offered by extension officers, formulation of bylaws, also further study is needed and awareness creation on the effect of climate change and the mitigation strategies.

\section{APA CITATION}

Kayombo, C., Komba, L., \& Kashindye, A. (2020). Climate Change Adaptation Strategies among Tobacco Small Scale Growers at Kiloleli Village in Sikonge District, Tanzania. East African Journal of Environment and Natural Resources, 2(2), 1-9. https://doi.org/10.37284/eajenr.2.2.149

\section{CHICAGO CITATION}

Kayombo, Canisius, Lambert Komba, and Almas Kashindye. 2020. "Climate Change Adaptation Strategies Among Tobacco Small Scale Growers at Kiloleli Village in Sikonge District, Tanzania”. East African Journal of Environment and Natural Resources 2 (2), 1-9. https://doi.org/10.37284/eajenr.2.2.149.

\section{HARVARD CITATION}

Kayombo, C., Komba, L. and Kashindye, A. (2020) "Climate Change Adaptation Strategies among Tobacco Small Scale Growers at Kiloleli Village in Sikonge District, Tanzania”, East African Journal of Environment and Natural Resources, 2(2), pp. 1-9. doi: 10.37284/eajenr.2.2.149.

\section{IEEE CITATION}

C. Kayombo, L. Komba, and A. Kashindye, "Climate Change Adaptation Strategies among Tobacco Small Scale Growers at Kiloleli Village in Sikonge District, Tanzania”, EAJENR, vol. 2, no. 2, pp. 1-9, May 2020.

\section{MLA CITATION}

Kayombo, Canisius, Lambert Komba, and Almas Kashindye. "Climate Change Adaptation Strategies Among Tobacco Small Scale Growers at Kiloleli Village in Sikonge District, Tanzania". East African Journal of Environment and Natural Resources, Vol. 2, no. 2, May 2020, pp. 1-9, doi:10.37284/eajenr.2.2.149.

\section{INTRODUCTION}

\section{Effect of Climate Change}

The consequences of the effect of climate change has been revealed to touch many people ranging from agricultural crop farmers and livestock keepers (Thornton \& Herrero, 2015). It has been stated that Some of the most important impacts of global climate change will be felt among the populations, predominantly in developing countries, referred to as "subsistence" or "smallholder" farmers. Their vulnerability to climate change comes both from being predominantly located in the tropics, and from various socioeconomic, demographic, and policy trends limiting their capacity to adapt to change (Nath \& Behera, 2011). Climate change refers to the changes in long-term trends in the average climate, such as changes in average temperatures (Wilson, 2006). The variation in the weather elements over a long time, whether due to natural variability or as a result of human activity entails climate change (Neil et al., 2017). A number of scholars such as Norrington-Davies \& Thornton (2011) have highlighted the emphasis on human activities as among factors leading to the alteration of climatic condition has regularly being discussed by a number of scholars. A study by Ochieng et al., (2016) estimated the effect of climate variability and change on revenue from all crops, maize and tea separately, using a household fixed effects estimator; climate variability and change affects agricultural production but effects differed across crops.

\section{Climate Change Adaptation Strategies}

Climate change adaptation is the adjustment in natural or human systems in response to actual or expected climatic events or their effects, which moderate harm or exploit beneficial opportunities. (Adger et al., 2007). Adaptation can include changes in behaviour, technology, institutions, policies, and other aspects of human systems (Descheenmaeker et al., 2016). Adapting to climate change involves the ability of a system to change in a way that makes it better equipped to manage its exposure and sensitivity to climate hazards and cope with adverse impacts (IPCC, 2012).

Decisions on the strategy of adaptation are often made by individuals, groups within society, 
organizations, and governments on behalf of society (Majule et al., 2013). Some adaptation measures may be taken at an individual level. Others like rainwater harvesting and investments, building dams that are more drought resistance require collective actions (Majule et al., 2013). With the prevailing status of climate change, societies have inherent capacities to adapt to climate change and develop different adaptation and mitigation strategies to combat climate change. They have developed knowledge, skills, technology, institutional arrangements and strategies that are important foundations for adapting to long-term climate change (Majule et al., 2013). Communities have always adapted to climate variations by making preparations based on their resources and knowledge accumulated through experience of past weather pattern. The adaptive measures that households use when faced with climate change could also differ in terms of their ease of implementation, equity effects, implementation and effect, the cost of implications, compatibility with other programs, and agencies implementing measures (Mbilinyi et al., 2013).

\section{Climate Change as a Global Issue}

Climate change is a global problem, although the associated impact and adaptation strategies vary across the globe level. Developing countries are expected to be severely affected by the impacts of climate change (Kurukulasuriya \& Mendelson, 2008; Roco et al., 2014). These countries are reported to be more vulnerable to climate change impacts because the majority of the population depend on rain-fed agriculture for food and livelihood (Nath \& Behera, 2011). Climate variability has a direct adverse influence on agriculture production in Africa because nearly $80 \%$ of agriculture production in these countries is rainfall and temperature-dependent (NorringtonDavies \& Thornton, 2011). Over the past few decades, the continent has experienced an increased number of warm days and decreased numbers of extremely cold days (Majule et al., 2013). The changes caused by the alteration of weather condition been recognized to alter the type of agricultural crops, cropping pattern and lead to the emergence of crop disease (Bosire, 2009).
Nicotiana tabacum L. (tobacco) is among crops that need a huge amount of woody resources (logs) for drying; also, large areas are cleared when preparing land for growing such crop, hence reducing the carbon sinks. On the other hand, the $N$. tabacum (tobacco) kilns release greenhouse gases. In recent years, Tanzania has experienced crop failure due to low rainfall and emerging crop disease in many parts (Lema \& Majule 2016). In Tanzania framework, impacts climate change are not less depressing, in that more than $75 \%$ of the countryside practices largely survival rain-fed agriculture (Tao \& Zhang, 2010). In an effort to contest environmental issues, Tanzania has signed a numeral of Multilateral Environmental Agreement (MEA) and developed the National Adaptation Program of Action (NAPA) (Roco et al., 2014). The tobacco production incurs harmful effects to environment ranging from tobacco growing, production and manufacturing such as massive use of water, deforestation and contamination of the air and water sources and others due to the use of agro-chemical that degrade the soil fertility. Tobacco workers and farmers often being unaware of the toxicity of product they are managing and has led to climate change and its effects (Tao \& Zhang, 2010). The small-scale tobacco growers at Kiloleli village face the effects of environmental degradation hence the need for adaptive strategies to cope with those effects becomes significant.

The most important economic activity at Kiloleli village is agriculture; tobacco is the most famous cash crop proceeded by livestock keeping and other small enterprises for income generation such as groundnut industry, maize and honey harvesting According to Jagoe et al., 2001), the data suggested(1) high rates of smoking among men in an urban area of East Africa; and (2) the importance of validating self-reports of smoking status, particularly among women. In recent years, observation and quick assessment have indicated and documented some changes in weather and climatic condition in many countries (Parmesan \& Yohe, 2003), even though scientific information remains inadequate. Such changes include long dry season, short-time heavy rainfall, increase in average temperature, unpredicted climate pattern and other. Various investigates have been conducted on the adaptation strategies to the 
climate change in other areas of the world, such as China (Tao \& Zhang, 2010). However, the Kiloleli village remains not explored for adaptation strategies to impacts of climate change. This study aimed to assess the adaptation strategies to the effects of climate change among tobacco growers at Kiloleni Village in Sikonge District. The study findings provide recommendations to agriculture, forestry experts and policymakers on the sustainable strategies to address climate change effect in the area affected to the effect of climate change (small scale tobacco growers to that specified area). The underlying specific objectives of this study were to determine the indicators of climate change, the effect of climate change on small scale tobacco growers and to determine the adaptation strategies to the effects of climate change. The research questions included (i) what the indicators of climate change are? (ii) what are the effects of climate change to small scale tobacco growers? and (iii) what are the adaptation strategies to effect of climate change to small scale tobacco growers?

\section{MATERIAL AND METHODS}

\section{Description of the Study Area}

This study was conducted at Kiloleli village, which is situated in Sikonge district. Its' geographical coordinates are $5^{\circ} 38^{\prime} 0^{\prime \prime}$ South, $32^{\circ} 46^{\prime} 0^{\prime \prime}$ East (United Republic of Tanzania, 2016). The Kiloleli village borders Nyahua forest reserve to the East, Kanyamsenga village to the South, Mibonompya village to the North, Mtakuja and Songambele villages to the west. According to United Republic of Tanzania (2002) and United Republic of Tanzania (2013), the total population of people at Kiloleli village was 2,304. But among all those villagers, only 156 were farmers known to be dealing with small tobacco ( $N$. tobaccum) growing.

Kiloleli lies in the region whose beekeeping is among sources of income through selling honey and beeswax. Fisher (1997), specified that Tabora Region Beekeepers Cooperative Society LTD (TBCS) in Tanzania had sold honey under the logo African Queen since the 1960's, and other societies also expanded in the 1980's where several organizations joined the exportation of the bee resources.
The major crops produced at Kiloleli are tobacco and other crops such as Zea mays (maize), Arachis hypogaea (groundnuts), Manihot esculenta (cassava) and Ipomoea batatas (sweet potatoes), Helianthus annuus (sunflower) and $N$. tabaccum (tobacco) as a cash crop. Livestock keeping is the second most important economic activity after agriculture in at Kilolile village. This activity is important as a source of food and an alternative source of income at household in the community. The type of livestock kept by residents at Kilolile village in Sikonge district include Bos taurus (cattle), Capra aegagrus hircus (goat), Ovis aries (sheep), Equus asinus (donkey), Sus scrofa domesticus (pigs), and Gallus domesticus (poultry).

\section{Sampling Techniques}

Simple random sampling was used to select households within the village to be interviewed, whereby thirty-four households (34) represented the total population. The simple random sampling reduces the potential for human bias in the selection of cases to be included in the sample; hence to provide a sample that is highly representative of the population being studied. Besides, it allows to make a generalization (Statistical inferences) from the sample to the population; and also, it requires little knowledge on the population in advance (Chaudron \& Carlier, 2014). This method was based on the principle that every unit of a population had an equal chance of being selected for the study. The village register was used to select the sample households in Kiloleli village.

The sample size of the population was calculated using Yamane's' formula (Yamane, 1967)

$$
\mathrm{n}=\frac{\mathrm{N}}{1+\mathrm{N}(\mathrm{e})^{2}}=\frac{156}{1+15(0.15)^{2}}=34
$$

Hence, the sample size was 34 households.

Where: $\mathbf{n}=$ sample size (total households to be interviewed); $\mathbf{N}=$ sampling frame; $\mathbf{1}=$ constant; $\mathrm{e}=$ allowable error. Yamane formula is a simple kind of simple statistical way of calculating the sample size. 


\section{Data Collection and Analysis}

Both primary and secondary data were collected. The primary data was collected through a semistructured interview with the sampled households. Secondary data were collected from the literature review from different sources such as books, reports, scientific journals, worldwide webs were used to collect secondary data. Statistical Package for Social Science (SPSS) and Microsoft Excel computer programs was used during data analysis. Specifically, in this study, the data were analyzed through descriptive statistics by calculating average, frequency, percentage. The findings have been presented in the form of tables and statements clarifying the findings.

\section{RESULTS AND DISCUSSION}

The study was conducted to assess the adaptation strategies to effects of climate change practised by tobacco growers at Kiloleli village in Sikonge district, Tabora region. A number of findings were revealed implying that the adaptation strategies to effects of climate change in association with the livelihood of the small-scale tobacco growers were significant in comparison to what is obtained from cultivation of tobacco. This is because the cultivation of tobacco is well associated with the climatic condition of an area. This chapter states the findings of the research based on the targeted specific objectives.

\section{Indicators of Climate Change}

Neil et al. (2017) revealed several factors that indicated the climate was changing; the indicators included greenhouses gases (GHG) emission levels; atmospheric GHG concentration levels; changes in the global mean temperature and sealevel rise; changes in regional climate variable; changes in the intensity or frequency of extreme events. Bryan et al (2013) conducted a study from various agroecological zones in Kenya, whereby farmers' perceptions of climate change, ongoing adaptation measures, and factors influencing farmers' decisions to adapt where examined, hence revealing results that showed that households faced considerable challenges in adapting to climate change, even though they were aware of the indicators of climate change. The findings of this study showed the indicators of climate change on small scale tobacco growers. Those indicators were expressed by the respondents as the sign that the climate was changing and affected the cultivation of tobacco. The indicators for climate change effects (Table 1) were increased in temperature (23.7\%), crop agriculture crop wilting (17.2\%), increase in insects $(12.9 \%)$, decrease in the river water table (10.8\%, soil dryness (8.6), strong wind (8.6\%), infertility of soil $(4.3 \%)$, crop dwarfing $(4.3 \%)$, low rainfall $(3.2 \%)$, increase of diseases (3.2\%) dryness of wells (2.2\%) and poor air quality $(1.1 \%)$.

Table 1: Showing percentage of indicators of climate change

\begin{tabular}{lll}
\hline Indicator & Frequency & Percentage (\%) \\
\hline Soil dryness & 8 & 8.60 \\
Agriculture crop wilting & 16 & 17.20 \\
Raise of temperature & 22 & 23.70 \\
Strong winds & 8 & 25.78 \\
Poor air quality & 1 & 3.24 \\
Decrease of water/stream level (dry) & 10 & 32.27 \\
Dryness of wells & 2 & 6.46 \\
Low rainfall & 3 & 9.68 \\
Increase of diseases & 3 & 9.68 \\
Dwindled growth of agriculture crops & 4 & 12.89 \\
Total & $\mathbf{3 1}$ & $\mathbf{1 0 0 . 0 0}$ \\
\hline
\end{tabular}




\section{Effects of climate change}

Worldwide, climate change has always shown effects on crop growers in terms of growth rate of crops and yield decrease (Roco et al., 2014). The findings from this study indicated that the effects of climate change existed at Kiloleli village in Sikonge district and thus affecting the tobacco small scale growers (Table 2). These revealed effects of climate change were drought, floods, hunger, soil erosion, a decrease of area for pasture, death of crops, dryness of river and production is still decreasing and increase of diseases to tobacco. Louse insects were known to be increasing day-today due to the climatic change and hence leading to the damage of the tobacco products. Diseases like yellowish, dwarfing, and Cercospora nicotianae (Frogeye disease) were common diseases affecting tobacco and other crops at Kiloleli village while in the previous years were not the case to agricultural crops. All these effects had impacted the livelihoods of the people of Kilolile village.

Table 2: Showing the effects of climate change at Kiloleli village

\begin{tabular}{lll}
\hline Effect of climate change & Frequency & Percentage $(\boldsymbol{\%})$ \\
\hline Dryness of rivers/streams & 11 & 13.1 \\
Decrease of green pastures & 9 & 10.7 \\
Low agriculture crop production & 8 & 9.5 \\
Prolonged drought & 8 & 9.5 \\
Soil erosion (wind and water runoff) & 6 & 7.1 \\
Death of agriculture crops & 6 & 7.1 \\
Floods & 6 & 7.1 \\
Low quality of crops & 2 & 2.5 \\
Increase of diseases & 9 & 9.5 \\
Soil infertility & 9 & 9.5 \\
Hunger & 12 & 14.1 \\
Total & $\mathbf{8 6}$ & $\mathbf{1 0 0 . 0 0}$ \\
\hline
\end{tabular}

\section{Climate Change Effects Adaptation Strategies}

Adaptation strategies to the effect of climate change to small scale growers are crop-livestock diversification, agroforestry, mulching, crop rotation, use of improved varieties, (Fadina \& Barjolle, 2018). In this study, the respondents mentioned that tree planting $(46.7 \%)$ was the best way of adapting to climate change compared to other strategies (Table 3). The other adaptation strategies to the effects of climate change were drought-resistant crop cultivation (17.8\%), education $(11.1 \%)$, agroforestry practices $(8.9 \%)$, formulation of bylaws $(6.7 \%)$, use of an alternative source of energy (4.4\%) and crop rotation (4.4\%).

Table 3: Climate change adaptation strategies

\begin{tabular}{lll}
\hline Adaptation strategy & Frequency & Percentage $(\boldsymbol{\%})$ \\
\hline Tree planting & 21 & 46.7 \\
Agroforestry practice & 4 & 8.9 \\
Use of alternative sources of energy & 2 & 4.4 \\
Cultivation of drought-resistant crops & 8 & 17.8 \\
Education to the local community & 5 & 11.1 \\
Crop rotation & 2 & 4.4 \\
\hline
\end{tabular}


East African Journal of Environment and Natural Resources, Volume 2, Issue 1, 2020

Article DOI: https://doi.org/10.37284/eajenr.2.2.149

\begin{tabular}{lll}
\hline Adaptation strategy & Frequency & Percentage $(\boldsymbol{\%})$ \\
\hline Formulation \& implementation of bylaws & 3 & 6.7 \\
Total & $\mathbf{4 5}$ & $\mathbf{1 0 0}$ \\
\hline
\end{tabular}

\section{CONCLUSION AND RECOMMENDATION}

Climate change has an influence on the small-scale tobacco growers at Kiloleli village in Sikonge district. There have been indicators for the climate to the tobacco growers like increase in temperature, agriculture crop wilting, increase in insects, decrease in the river water table, soil dryness, strong wind, infertility of soil, crop dwarfing, low rainfall, an increase of diseases, dryness of wells, and poor air quality. There is no way that the smallscale growers can run away from the effects of climate change, rather than taking into account the adaptation measures. Climate change has been revealed to affect the tobacco small scale growers. This study recommends the following, among many others. Extension services are required to the villager about the effect of climate change and how to adapt climate change effects on their tobacco and other crops. Application of agroforestry with offer shade to various lower-growing crops. Also, trees will offer wood materials to be used when drying tobacco leaves and thus reducing pressure on natural forests. Creation of bylaws to be applied for farmers or villagers who damage natural forests, at the same time not planting trees, encourage plant collecting inventory to determine their conservation status to include endemism, critically endangered, endangered, threatened, near threatened as such information can contribute to conservation strategies seriously to encourage tree planting at homesteads as a source of $N$. tabacum drying kilns while natural vegetation is rescued and hence regulating rainfall.

\section{REFERENCE}

Adger, W. N., Agrawala, S., Mirza, M. M. Q., Conde, C., Brien, O., Pulhin, K., Pulhin, J., Pulwarty, R., Smith, B. \& Takahashi, K. (2007). Assessment of adaptation practices, options, constraints and capacity. Contribution of Working Group II to the Fourth Assessment Report of the Intergovernmental Panel on Climate Change (pp. 717 - 743). Cambridge, UK: Cambridge University Press.
Admassie A, Adenew B and Tadege A. (2008). Perceptions of stakeholders on climate change and adaptation strategies in Ethiopia. International Food Policy Research Institute and Ethiopian Economic Association.

Bosire, J. (2009). Climate Change Favours crops. The East African recast and replace, Kenya.

Chaudron, R., \& Carlier, K. (2014). The advantages of random sampling versus cutting-of-the-tail: the application of stratified sample design for the collection of data on special financial institutions in the Netherlands. Statistics and Information Division of the Nederlandsche Bank.

Descheemaeker, K., Oosting, S. J., Tui, S. H. K., Masikati, P., Falconnier, G. N., \& Giller, K. E. (2016). Climate change adaptation and mitigation in smallholder crop-livestock systems in sub-Saharan Africa: a call for integrated impact assessments. Regional Environmental Change, 16(8), 2331-2343.

Fadina, A. M. R. \& Barjolle, D. (2018). Farmers' adaptation strategies to climate change and their implications in the Zou Department of South Benin. Environments, 5(1), 15.

Fisher, E. (1997). Beekeepers in the global'Fair Trade'market: A case from Tabora Region, Tanzania. International Journal of the Sociology of Agriculture and Food, 6, 109-159.

IPCC. (2012). Managing the Risk of Extreme Events and Disasters to Advance Climate Change Adaptation Special Report of Working Groups I and II of the Intergovernmental Panel on Climate Change. New York, NY: Cambridge University Press.

Jagoe, K., Edwards, R., Mugusi, F., Whiting, D., \& Unwin, N. (2002). Tobacco smoking in Tanzania, East Africa: population based smoking prevalence using expired alveolar 
carbon monoxide as a validation tool. Tobacco Control, 11(3), 210-214.

Kurukulasuriya, P., \& Mendelsohn, R. (2008). Crop switching as a strategy for adapting to climate change. African Journal of Agricultural and Resource Economics, 2(3112016-5522), 105-126.

Lema, M. A., \& Majule, A. E. (2009). Impacts of climate change, variability and adaptation strategies on agriculture in semi-arid areas of Tanzania: The case of Manyoni District in Singida Region, Tanzania. African Journal of Environmental Science and Technology, 3(8), 206-218.

Majule AE, Stathers T, Lamboll R, Liwenga ET, Ngongondo C, Kalanda- Joshua M, Swai E and Chipungu F. (2013). Enhancing capacities of individuals, institutions and organisations to adapt to climate change in the agricultural sector using innovative approaches in Tanzania and Malawi. World Journal of Agricultural Sciences, 1(6), 220 - 231.

Mbilinyi, A., Saibul, G. O., \& Kazi, V. (2013). Impact of climate change to small scale farmers: voices of Farmers in village communities in Tanzania. The Economic and Social Research Foundation Discussion Paper No, 47.

Nath, P. K., \& Behera, B. (2011). A critical review of impact of and adaptation to climate change in developed and developing economies. Environment, development and sustainability, 13(1), 141-162.

Norrington-Davies, G., \& Thornton, N. (2011). Climate change financing and aid effectiveness. Tanzania Case Study. Organization for Economic Cooperation and Development - Development Assistance Committee.

Ochieng, J., Kirimi, L., \& Mathenge, M. (2016). Effects of climate variability and change on agricultural production: The case of small-scale farmers in Kenya. NJAS-Wageningen Journal of Life Sciences, 77, 71-78.
O'Neill, B. C., Oppenheimer, M., Warren, R., Hallegatte, S., Kopp, R. E., Pörtner, H. O., ... \& Mach, K. J. (2017). IPCC reasons for concern regarding climate change risks. Nature Climate Change, 7(1), 28-37.

Parmesan, C., \& Yohe, G. (2003). A globally coherent fingerprint of climate change impacts across natural systems. Nature, 421(6918), 3742.

Roco, L., Engler, A., Bravo-Ureta, B. E., \& JaraRojas, R. (2015). Farmers' perception of climate change in mediterranean Chile. Regional environmental change, 15(5), 867-879.

Roco, L., Engler, A., Bravo-Ureta, B., Jara-

Tao, F., \& Zhang, Z. (2010). Adaptation of maize production to climate change in North China Plain: quantify the relative contributions of adaptation options. European Journal of Agronomy, 33(2), 103-116.

Thornton, P. K., \& Herrero, M. (2015). Adapting to climate change in the mixed crop and livestock farming systems in sub-Saharan Africa. Nature Climate Change, 5(9), 830-836.

United Republic of Tanzania (2002). Population and Housing Census 2002 - IPUMS Subset. Integrated Public Use Microdata Series (IPUMS) Centre. National Bureau of Statistics, Minnesota Population Center.

United Republic of Tanzania (2016). Ministry of works, transport and communication Tanzania

United Republic of Tanzania (URT). (2007). National adaptation plan of action (NAPA). Vice President's Office, Division of Environment. Dar es Salaam, Government printers.

United Republic of Tanzania. (2013). Population and Housing Census, Population Distribution by Administrative Areas for 2012. National Bureau of Statistics Ministry of Finance Dar es Salaam, Office of Chief Government Statistician President's Office, Finance, Economy and Development Planning Zanzibar. 
East African Journal of Environment and Natural Resources, Volume 2, Issue 1, 2020

Article DOI: https://doi.org/10.37284/eajenr.2.2.149

Wilson, E. (2006). Adapting to climate change at the local level: the spatial planning response. Local environment, 11(6), 609-625.

Yamane, T. (1967). Statistics: An Introductory Analysis, 2nd Edition. New York: Harper and Row. 